\title{
Physicochemical Mechanisms of Synergistic Biological Action of Combinations of Aromatic Heterocyclic Compounds
}

\author{
Maxim P. Evstigneev \\ Department of Physics, Sevastopol National Technical University, Sevastopol 99053, Ukraine \\ Correspondence should be addressed to Maxim P. Evstigneev; max_evstigneev@mail.ru
}

Received 20 December 2012; Accepted 14 January 2013

Academic Editor: Jacek Piosik

Copyright (C) 2013 Maxim P. Evstigneev. This is an open access article distributed under the Creative Commons Attribution License, which permits unrestricted use, distribution, and reproduction in any medium, provided the original work is properly cited.

The mechanisms of synergistic biological effects observed in the simultaneous use of aromatic heterocyclic compounds in combination are reviewed, and the specific biological role of heteroassociation of aromatic molecules is discussed.

\section{Introduction}

Biologically active aromatic compounds (BACs) constitute an important group of pharmaceutical drugs, extensively utilized in various medicinal applications. Typical examples are the aromatic anthracycline antibiotics (daunomycin, doxorubicin, topotecan, mitoxantrone, etc.), which are effective against solid tumors and leukemia; quinolone antibiotics (norfloxacin, ofloxacin, etc.), exerting a wide spectrum of antibacterial activity; aromatic vitamins (riboflavin, nicotinamide, etc.), used as antioxidants in chemotherapy; methylxanthines which are present in high concentrations in food sources; and many other aromatic compounds, possessing useful medicobiological properties (Figure 1) $[1,2]$.

Practically all of the aromatic antitumour drugs exert toxic side effects at high dose, which limits their use in clinical practice. In particular, the most effective antitumour anthracycline antibiotics are characterized by remarkable cardiotoxicity being developed within the first 2-3 days of the chemotherapy course with the possibility of lethal outcome at overdosing [3]. However, the risk of side toxicity may be significantly lowered, or the medicobiological effect amplified, by combination of these antibiotics with other drugs, for instance, with various antitumour aromatic antibiotics (known as a combinational chemotherapy) or vitamins [4-6].

Aromatic molecules are commonly represented in a form of planar heterocyclic structures, having a chromophore as a main part composed of conjugated $\mathrm{C}=\mathrm{C}$ double bonds with delocalized $\pi$-electrons. Numerous investigations of the behaviour of aromatic molecules in aqueous solutions have shown that vertical-stacking interactions for such compounds are the most important in solution resulting in the formation of "sandwich"-type aggregates (Figure 2) with more than two monomers in the general case [6]. A distinction is usually made between self-association (interaction of identical molecules, Figure 2(a)) and hetero-association (interaction of different molecules, Figure 2(b)) [7, 8].

Although the mechanisms of biological action of aromatic BACs is not completely known, literature review suggests that the molecular basis of biological action of aromatic drug molecules in many cases is explained at the level of DNA complexation, which may be significantly modulated by the self- and hetero-association $[6,9]$. The current paper discusses the mechanisms of synergistic action of DNAtargeting aromatic heterocyclic compounds when present in a biosystem in various combinations. The discussion will be focused on the most important combinations of drug-drug, drug-vitamin, and drug-methylxanthine systems exerting synergistic effect in vivo and/or in vitro and in many cases allowing its interpretation on molecular level.

\section{One-Component Systems}

The interaction of identical biologically active aromatic molecules in aqueous solution (self-association) has long been the subject of biophysical investigations mainly as a means to get more insight into the vertical stabilization 


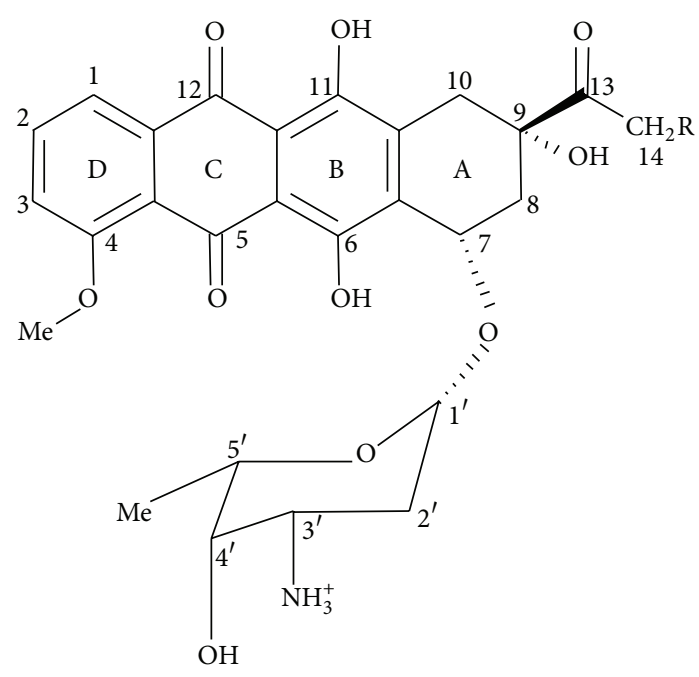

(a)

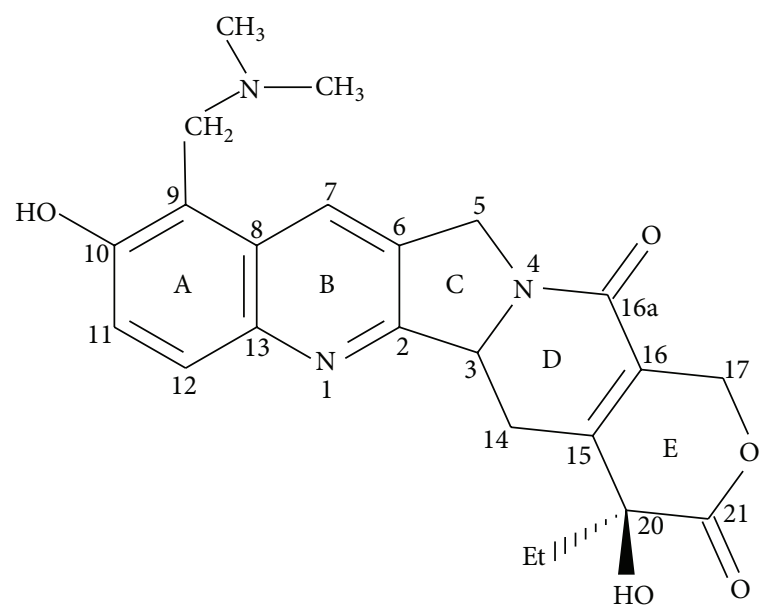

(b)<smiles>O=C1c2c(O)ccc(O)c2C(=O)c2c(NC=CNCC=CNC=CCO)ccc(NC=CCO)c21</smiles>

(c)

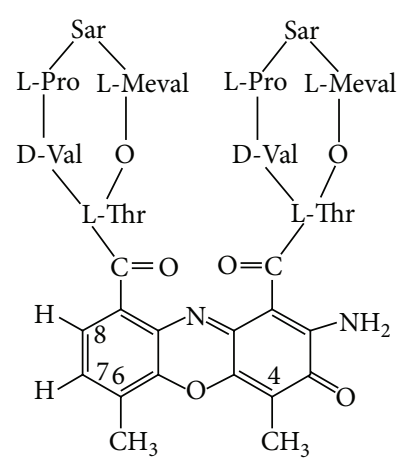

(d)<smiles>CCn1cc(C(=O)O)c(=O)c2cc(F)c(N3CCNCC3)cc21</smiles>

(e)

FIGURE 1: Structures of typical aromatic drug molecules: (a) daunomycin ( $\mathrm{R}=\mathrm{H})$, (a) doxorubicin ( $\mathrm{R}=\mathrm{OH}$ ), (b) topotecan, (c) mitoxantrone/novantrone, (d) actinomycin D, and (e) norfloxacin.

of nucleic acids (the self-association of derivatives of the nitrogen bases) [10], or as a preliminary stage followed by micellization of certain biologically important molecules in aqueous media [11, 12], or to increase the accuracy of physicochemical parameters obtained by various experimental methods [13]. In particular, it has long been known that a correct thermodynamical analysis of the interaction of anthracycline antibiotics with DNA requires their selfassociation to be taken into account, if the range of experimental concentrations is in the range of dozens of $\mu \mathrm{M}$ or higher $[13,14]$.

There are also many reports suggesting that the selfassociation of aromatic molecules can have its own biological significance. It was shown that the kinetics of transport of doxorubicin through cell membranes features a saturation profile, which depends on the concentration of the antibiotic and the temperature of the solution [15]. This result was not in line with the well-recognized passive diffusion of DOX molecule through lipid layer, which had led to the assumption that the aggregation of the antibiotic was the main factor affecting the characteristics of its transport through cell membrane [15]. It is also well known that the group of anthracycline antibiotics and its derivatives accumulate inside a cell $[16,17]$. Although the mechanism of this effect is not yet understood, it may lead to an excess of intracellular concentrations of the antibiotic hundreds of times greater than concentrations in blood plasma [16-18]. Presumably, this is considered to be the basic reason for the observed aggregation of the anthracycline derivative, the antibiotic novantrone, in intracellular media even under physiological concentrations [18].

A rather specific mechanism of biological action was suggested for the quinolone antibiotic, norfloxacin $[19,20]$. According to the current view, norfloxacin forms aggregates composed of a few antibiotic molecules, which complex with a DNA-enzyme complex, when the gyrase is cutting both DNA chains [21]. It was implied [19, 20] that the optimal geometry of the aggregate of NOR molecules, which effectively binds with the DNA-enzyme complex, has the form of a dimer of the antibiotic molecules, in which the planes of their chromophores are parallel to each other (vertically stacked). It is thought that when the DNA strands 

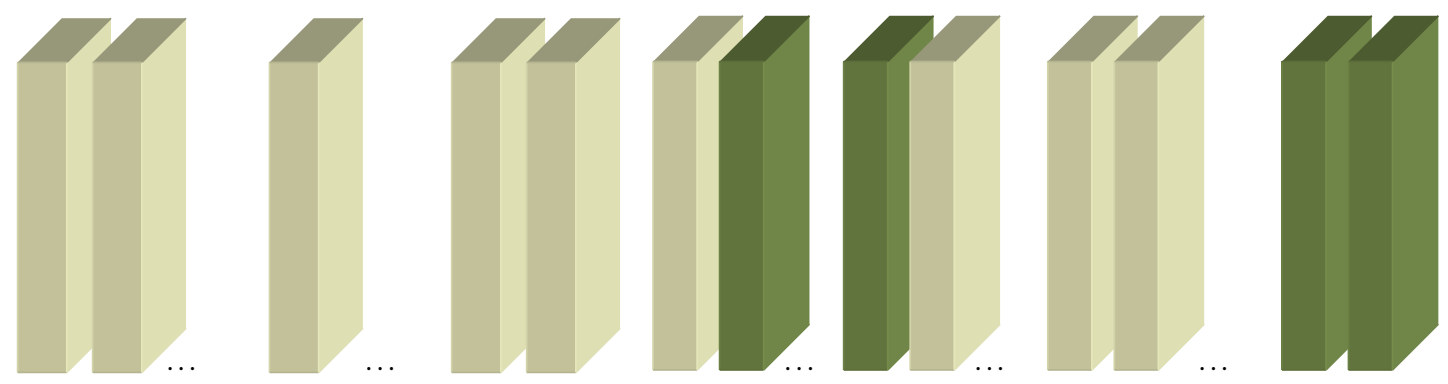

(a)

(b)

FIGURE 2: (a) Self-association and (b) hetero-association of planar aromatic molecules.

are being cut, the cavity being formed has dimensions very similar to the dimensions of the dimer of NOR molecules. Such mechanism may explain the experimentally observed cooperative character of the antibiotic binding with the DNAgyrase complex $[19,20]$.

Molecular self-association is currently considered as one of the important factors determining the color change of certain plants [22]. It is known that the pigments responsible for the color of plants belong to a group of anthocyanin molecules, the structure of which contains an aromatic flavyl chromophore. It is thought that the self-association of anthocyanines by means of vertical-stacking results in copigmentation and corresponding change in spectral properties of the complex formed [22-24].

The effect of the self-association is also viewed in terms of one of the possible mechanisms of solubilization of poorlysoluble aromatic drugs in the presence of hydrotropic agents $[25,26]$. The self-association of a hydrotropic agent, present in solution at high concentration, leads to the formation of molecular aggregates like micelles, complexing guest aromatic molecules due to the hydrophobic effect. This process increases the solubility of a drug added into solution and elevates its bioavailability and chemotherapeutic index [27].

And, finally, the influence of the self-association on drugs' pharmacokinetics is also worth mentioning, which affects their bioavailability and, consequently, biological effect $[28,29]$.

In general, the interconnection of medicobiological activity of aromatic drugs and their propensity to self-associate in solution appears to be specific to any drug. It is, nevertheless, obvious that accounting for self-association is an important point in conducting any biophysical study involving biologically active aromatic drugs.

\section{3. "Aromatic Drug-Methylxanthine" Systems}

Early investigations have shown that some methylxanthines (caffeine, pentoxifylline, and others) at concentrations of an order of ca. $1 \mathrm{mM}$ exert a "protector" action in vitro with respect to cellular DNA in the presence of aromatic cytotoxic agents [30-35]; that is, which they "protect" the integrity of DNA resulting in lowering of the net toxicity. At higher concentrations (>10 mM), caffeine potentiates the toxic effect [36]. To date, it is known that, on simultaneous addition or right after the main drug, CAF diminishes the toxicity of the antitumour antibiotics doxorubicin [30, 31, 33, 37-39], mitoxantrone $[32,33,37,39]$, ellipticine $[33,38]$, amsacrine [34], camptothecins [38, 40], and phenothiazine drugs [41] as well as the aromatic mutagen ethidium bromide [42] and aromatic neurotoxin tetrahydropyridine [43]. The "protector" effect has also been reported with respect to the aromatic mutagen quinacrine, ICR-191, ICR-170, IQ-type heterocyclic aromatic amines, and neocarzinostatin in the presence of caffeine and its derivatives [44-47]. Two basic mechanisms responsible for the observed effects in cells have initially been suggested $[32,33]$ : hetero-association of caffeine and the aromatic drug and competitive binding of CAF with DNA (Figure 3). Hetero-association lowers the number of monomers of aromatic drug in solution, which are available to bind with DNA - this process was termed the "interceptor" action of CAF with respect to the drug [32, 33, 37, 48, 49]. The complexation of CAF with DNA partially removes the drug molecules bound with DNA, thus lowering the fraction of drug-DNA complexes-this process was termed the "protector" action of CAF with respect to DNA [32, 49]. In both cases, the fraction of the drug-DNA complexes is decreased in the presence of caffeine and, consequently, the biological activity of the aromatic drug changes as well. The cumulative effect of the displacement of ligand from DNA has been observed by various experimental techniques [50-52] and was even considered as a practical method of "bleaching" (in fluorescence terms) of cellular DNA from the bound drug for further recycling of that cell culture (which was elegantly demonstrated using propidium iodide and aminoactinomycin as an example [52]). Potentially, this effect can be used as a strategy of regulation of the medicobiological activity of aromatic drugs in clinical practice, say, for example, in the reduction of the consequences of drug overdosing during the chemotherapy or in the production of antimutagenic effects in vivo $[37,53]$, regulate the rate of drug degradation $[54,55]$, and optimize the solubility of the drug [56]. 


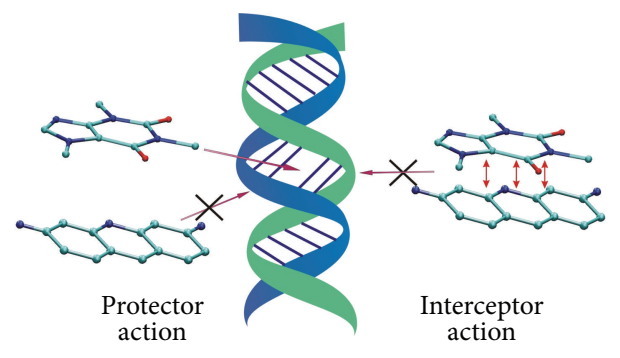

FIgURE 3: Protector and interceptor mechanisms of caffeine action on aromatic drug complexation with DNA.

The importance of the interceptor mechanism has been confirmed by numerous physicochemical investigations of the complexation of various aromatic drugs with caffeine and its derivatives $[6,33,37-40,43-53,57-70]$ and may now be considered as a generally accepted view. Although there is a general agreement between different research groups on the role of the interceptor mechanism with respect to drugmethylxanthine systems, the contribution of the protector mechanism is still under debate. Such a view is based predominantly on qualitative assumption of negligible binding of CAF with nucleic acids when compared with the ligand complexation with the same DNA, which makes improbable the displacement of the drug due to their competition $[32,66]$. However, early spectroscopic [71-73] and DNA unwinding [74] experiments have demonstrated the ability of CAF to bind with DNA. Recent investigations have shown that CAF exhibits the same order of magnitude of equilibrium binding constant with DNA as the hetero-association constant of CAF with aromatic ligands $[49,75]$; it should also be taken into account that the typical concentrations of CAF in in vitro experiments on cell lines are at least three orders of magnitude higher than typical concentrations of the drug (millimoles and micromoles, resp. [32, 33]). It means that the very low affinity of caffeine to DNA as compared to the affinity of the ligand to DNA can be compensated for by the much greater concentration of caffeine compared to the ligand. Hence, the fraction of CAF molecules bound with DNA may be of the same order of magnitude as the fraction of the heterocomplexes; that is, the "interceptor" and "protector" mechanisms may, in principle, be equally effective. The interceptor/protector approach was developed in $[6,49,53,62,65,67,69,76]$ and resulted in the separation of the contribution of the interceptor and protector mechanisms into the net effect of drug removal from DNA on the addition of methylxanthine. Moreover, these studies have demonstrated the possibility of quantitative estimation of the in vitro change of biological effect in drug-methylxanthine systems $[6,67,76]$. Unfortunately, direct experimental measurement of the contribution of these mechanisms is currently not possible, although recent investigations [69] have shown that the exclusion of the protector mechanism leads to underestimation of experimentally observed molar absorption in three-component drug-interceptor-DNA system.

Importantly, the above-formulated molecular mechanisms of methylxanthine action, as well as the cytotoxic effects, have been reported specifically for the group of aromatic intercalators and are commonly not observed for nonaromatic compounds.

\section{4. “Aromatic Drug-Vitamin" Systems}

As a result of previous investigations on the interaction of aromatic vitamin riboflavin, its analogue, flavinmononucleotide, and its derivatives, with other aromatic BACs in aqueous solution carried out by various experimental methods, several possible mechanisms of interaction of the molecules have been suggested, to explain the observed alteration of medicobiological action of aromatic BACs in the presence of the vitamin.

4.1. Anthracyclines-Riboflavins. The observed lowering of the toxicity of the antibiotic doxorubicin in the presence of riboflavin [77-79] may originate from (i) the antioxidant action of riboflavin, capable of removing reactive oxygen and free radicals, formed as a consequence of DOX metabolism in the cell, and (ii) the ability of riboflavin to form bimolecular complexes with DOX. Direct interaction of DOX with riboflavin derivatives, FMN and FAD, and their competition for the binding sites on flavin-containing enzymes were also noted $[78,80-83]$ in terms of a possible mechanism for the myopathy developed during the utilization of the antibiotic. It was suggested that this side effect is triggered by the suppression of FAD biosynthesis from riboflavin and, as a consequence, leads to change in the oxidative potential of flavoenzymes and metabolic energetics in the cell $[78,80]$.

The investigations of riboflavin-dependent photodestruction of DOX have shown that the maximal rate of photolytic degradation of the antibiotic is reached only by the time when majority of DOX molecules form hetero-complexes with the vitamin, followed by doxorubicin oxidation and decomposition of the anthraquinone portion of the molecule [78]. Interestingly, the chemical degradation of the aromatic agent, complexed with vitamin $\mathrm{B}_{2}$, was also reported with respect to another aromatic compound, the end metabolite of benzopyrene possessing carcinogenic activity [84].

4.2. Benzopyrenes-Riboflavins. The formation of stacked hetero-complexes between BP and flavin-mononucleotide was suggested [84], with the possible formation of an intermolecular hydrogen bond to stabilize the complex, pulling together the epoxy group of BP and the phosphate group of FMN. Formation of such a complex, characterized by functional groups being spatially close to each other, promotes the participation of the phosphate group of FMN and the epoxy group of benzopyrene in further acid-catalyzed hydrolysis leading to the chemically inactive and noncarcinogenic tetraole [84].

The possibility of complexation between riboflavin and benzopyrene was also noted [85], where the action of riboflavin on its simultaneous consumption with ${ }^{3} \mathrm{H}$-labeled $\mathrm{BP}$, whose chemically-active metabolites damage DNA, was observed in vivo. A remarkable decrease in BP binding with DNA was found in all types of tissues, particularly in 
parts of metabolic activity of the drug [85]. The authors of work [85] assumed that the decrease in BP binding with DNA on increasing the concentration of riboflavin is due to the formation of complexes between the chemically active metabolites of BP and free (unbound) riboflavin and its derivatives, which are formed in physiological media on administration of the vitamin. Thereby, the utilization of the vitamin facilitates the lowering of BP metabolite binding with cellular DNA and quick removal of radioactivity in tissues.

4.3. Beta-Carbolines with Flavin Derivatives. When antidepressants (which also include a group of betacarbolines) are used in the treatment of depression and Parkinson's disease, a suppression of the enzyme activity of monoaminooxidasea flavoenzyme which catalyzes the oxidative desamination of certain important biogenic amines-is observed [86]. In order to understand the molecular mechanism of this effect, an investigation of the interaction of a series of structurally selected BCs and indoles with two typical representatives of the flavine family (FN), riboflavin and flavinemononucleotide, was conducted [86-90]. The formation of 1:1 nonfluorescent molecular complexes was observed and the equilibrium constants and thermodynamical parameters of complexation were calculated. As a result, it was found that FMN forms more stable hetero-complexes than RBF with the series of $\mathrm{BC}$ derivatives. The authors tried to correlate the FN-BC complexation with the suppression of MAO and came to a conclusion that a sequence of FN-BC complexation constants as a function of aromaticity of the $\mathrm{BC}$ chromophore corresponds to the change in MAO activity. It was suggested that betacarbolines are able to compete with the amines on binding with MAO flavine residues and, thereby, block the active centre of the enzyme.

4.4. Other Aromatic Drugs with Riboflavins. The abovereviewed studies of possible mechanism of the influence of flavines on biological activity of aromatic drugs enable to conclude that for the "Aromatic drug-vitamin" system the most probable mechanisms of the observed synergetic biological effect are the direct interaction between the vitamin and the drug and their competition for the biological receptor DNA or protein. In fact, this had stimulated further investigation of the complexation of riboflavins with aromatic drugs (i.e., the hetero-association).

Perhaps, the most detailed recent investigations of heteroassociation of RBF/FMN-drug systems were carried out by NMR spectroscopy. In the study of the interaction of FMN with the antibiotics, DAU, AMD, NOR, TPT, and NOV [9196], and mutagens, ethidium bromide and proflavine [97], the formation of stable hetero-complexes in solution was found. These results were further transferred to three-component systems drug-riboflavin-DNA where riboflavin acts as an interceptor molecule. Although the RBF/FMN binding with DNA is thought to be relatively small and so far observed only on the level of oligonucleotides [92], theoretical evaluation of the contribution of interceptor and protector mechanisms into change of biological effect of the drug on addition of FMN was accomplished $[6,76,92]$. At this point it is worth noting that there are many reports in the literature (see, e.g., $[79,85])$, on anticarcinogenic or antimutagenic effect of riboflavin against nonaromatic drugs, though in these publications totally different mechanisms of the observed synergetic effects, different for different drugs, are commonly discussed. It is important that the hypothesis on the interceptor/protector mechanism in drug-riboflavin-DNA systems is in full agreement with the views on aromatic drug binding with DNA in the presence of caffeine sketched out before, and, presumably, originates from a general property of the group of aromatic biologically active compounds, which form sandwich-type complexes in solution and bind with DNA.

\section{5. "Drug-Drug" Systems}

In the current scientific literatures there is no clear understanding of the mechanisms and reasons for the influence of the combination of aromatic antitumour drugs on the experimentally observed medicobiological effect as a result of their simultaneous administration. The complexity of interpretation of the synergism of such aromatic drugs is thought to be due to the fact that the molecular targets of their action in the cell may be completely different and not always unambiguously determined, and the fact that the mechanism of action of each of the drugs is not usually known. A typical example is the group of well-studied anthracycline antibiotics, for which at least two completely different mechanisms are discussed as being most important when explaining their antitumour activity: intercalation into DNA and the formation of free radicals [3]. We shall briefly review the available literature on the interpretation of the effects at the molecular level of the mutual action of aromatic antitumour drugs.

Combinational chemotherapy, which is technically grounded in the administration of a combination of drugs to an organism, depends on the type of malignant tumour and specific regimen of the therapy. The various drugs may be administered either sequentially or simultaneously $[1,2]$.

The concentrations in the dose of aromatic antibiotics, such as AMD, NOV, or the anthracyclines, are, as a rule, in the millimolar concentration range $[1,2]$, which implies the possibility of direct interaction between the administered drugs at the initial stage of their distribution throughout the organism. At least two biologically important consequences of such interaction might be expected. First, the rate of metabolic activation/deactivation in a biological fluid may be significantly changed compared to the kinetics of transformation of the free antibiotic in physiological media. Such a mechanism was previously used to interpret the reduction in toxicity of doxorubicin and a set of aromatic carcinogens in the presence of the aromatic vitamin riboflavin [78, 84]; moreover, the complexation of the vitamin with the drug catalizes the degradation reaction of the drug in solution. Second, the rate of absorption of various drugs immediately after their administration into an organism may be altered as a result of the interaction between them. At present, such a mechanism is thought to be the most important for interpreting the change in pharmacokinetic parameters of aromatic 
antibiotics on the consumption of food; a typical example is the direct interaction of the drug and of methylxanthines, which enter the organism in great amounts in food [37, 98, 99]. The possibility of such direct noncovalent interaction of aromatic drugs was investigated in detail in [100-103] resulting in conclusion that tight hetero-complexes may be formed between the drugs in solution.

An alternative mechanism of the mutual action of antitumour drugs may operate when the compounds under study are characterized by mutually opposite and simultaneously mutually complementary routes of metabolic activation. Thus, for example, doxorubicin is bioactivated by NADPH cytochrome P-450 reductase, whereas the antibiotic amsacrine is, instead, reversibly oxidized to quinone diimine. As a result of that, DOX and AMSA are able to form redox pair, presumably inducing one- and two-strand breaks in DNA molecule more effectively [104].

Positive medicobiological effect may be achieved by selection of antitumour drugs, specifically different in their physicochemical properties. Certain combinations of aromatic drugs have been discovered, which reduce the toxicity of each other on simultaneous administration into organism and in this sense are characterized by lowered chemotherapeutic index, for instance, the combination of camptothecin and chloroquine [105]. At the same time, the chloroquine molecule, in contrast to camptothecin, represents chemically a weak base and does not enter solid tumours, which have acidic internal media. Hence, the toxicity of camptothecin is maintained at the same level with respect to solid tumours and independent on the presence of chloroquine, whereas the toxicity with respect to normal tissues is lowered due to chloroquine [105]. The absence of the mentioned specificity of action on tumours, in general, lowers the medico-biological effect of the combination, for example, on replacing the chloroquine by aclarubicin [106], which is very important for the design of optimal strategy of chemotherapy on the basis of these compounds.

The majority of the aromatic antitumour drugs discussed so far exerts their action by complexation with nucleic acids; therefore, in many cases the synergism of their antitumour action appears at the DNA level. In cases where the aromatic intercalators used in the combination do not exert any clear specificity towards DNA base sequences (which is often the case) and possess mutually opposite electronic donor-acceptor properties, normally absent on their separate complexation with DNA. For a combination of aromatic compounds such a cooperative effect was reported for the mixture of "amsacrine-ethidium bromide" (EB), which was interpreted to be the consequence of the formation of a charge-transfer pair when both molecules are simultaneously intercalated in the neighbouring sites of DNA, as detected by EB fluorescence decay $[107,108]$. Such an electronic interaction, which is attractive in origin, increases the stability of AMSA-EB-DNA complex and explains the observed cooperativity.
The interaction of intercalated ligands may also occur irrespective of their physicochemical properties, and in the majority of cases is explained in terms of specific structural changes in the DNA double helix, induced by each ligand separately. Such a mechanism was suggested as primarily important for interpretating the improved toxic effect of the DAU-AMD combination [109] and also for the spectrophotometrically detected effect of AMD removal from DNA by daunomycin, ethidium bromide, and mitramycin [110]. It should be noted that the distortion of the DNA structure at the site of binding is also considered to be a key mechanism in the observed biological synergism on combination of aromatic intercalators and the nonaromatic externally binding antibiotics like distamycin or Hoechst 33258 [111].

A specific interaction between DNA-intercalated aromatic ligands may feature a covalent type of binding under certain conditions. A typical example is the combination of the two anthracycline antibiotics, DAU and DOX, which on intercalation in close vicinity to each other form a highly stable complex with DNA in the presence of residual amounts of formaldehyde $[112,113]$.

\section{Conclusions}

In summary, it may be concluded that the physical mechanisms of mutual influence of aromatic heterocyclic compounds on the medico-biological activity of each other may feature either a covalent or noncovalent type of action, exerted in specific and nonspecific forms. However, the fundamental similarity of the mechanisms originates from the physical interaction of aromatic molecules in mixed solution either at the nucleic acid level or at the level of direct interaction between the solute molecules. Taking into account the results of the brief survey of the mechanisms of the change in biological activity of aromatic drugs in the presence of other aromatic molecules, it may be assumed that aromatic drugs interact in solution via hetero-association and exert a mutual influence on complexation with DNA, which may, at least in part, contribute to the observed biological synergism when they are used in combination.

\author{
Abbreviations \\ BACs: Biologically active aromatic compounds \\ DOX: Doxorubicin \\ DAU: Daunomycin \\ NOR: Norfloxacin \\ AMD: Actinomycin \\ RBF: Riboflavin \\ FMN: Flavin-mononucleotide \\ FAD: Flavin-adenine dinucleotide \\ NOV: Mitoxantrone \\ CAF: Caffeine \\ BP: Benzopyrene \\ MAO: Monoaminooxidase \\ BC: Betacarbolines \\ AMSA: Amsacrine \\ TPT: Topotecan.
}




\section{References}

[1] E. Chu and V. T. DeVita, Physicians' Cancer Chemotherapy Drug Manual, Jones and Bartlett, 2003.

[2] I. H. Stockley, Stockley's Drug Interactions, Pharmaceutical Press, 6th edition, 2002.

[3] R. D. Olson and P. S. Mushlin, "Doxorubicin cardiotoxicity: analysis of prevailing hypotheses," FASEB Journal, vol. 4, no. 13, pp. 3076-3086, 1990.

[4] D. J. Stewart, D. J. Perrault, J. A. Maroun, and B. M. Lefebvre, "Combined mitoxantrone plus doxorubicin in the treatment of breast cancer," American Journal of Clinical Oncology, vol. 10, no. 4, pp. 335-340, 1987.

[5] L. H. Baker, J. Frank, G. Fine et al., "Combination chemotherapy using adriamycin, DTIC, cyclophosphamide, and actinomycin $\mathrm{D}$ for advanced soft tissue sarcomas: a randomized comparative trial. A phase III, Southwest Oncology Group Study (7613)," Journal of Clinical Oncology, vol. 5, no. 6, pp. 851-861, 1987.

[6] M. P. Evstigneev, DNA-Binding Aromatic Drug Molecules: Physico-Chemical Interactions and Their Biological Roles, Lambert Academic Publishing, 2010.

[7] D. B. Davies, D. A. Veselkov, and A. N. Veselkov, "Structure and thermodynamics of the hetero-association of aromatic molecules in aqueous solution determined by NMR spectroscopy," Molecular Physics, vol. 97, no. 3, pp. 439-451, 1999.

[8] D. B. Davies, D. A. Veselkov, V. V. Kodintsev, M. P. Evstigneev, and A. N. Veselkov, "1 H NMR investigation of the heteroassociation of aromatic molecules in aqueous solution: factors involved in the stabilization of complexes of daunomycin and acridine drugs," Molecular Physics, vol. 98, no. 23, pp. 1961-1971, 2000.

[9] S. Neidle and M. J. Waring, Molecular Aspects of Anti-Cancer Drug Action, Macmillan, 1983.

[10] P. O. P. Ts'o, "Bases, nucleosides, and nucleotides," in Basic Principles in Nucleic Acid Chemistry, vol. 1, pp. 453-584, Academic Press, San Diego, Calif, USA, 1974.

[11] D. Attwood, "The mode of association of amphiphilic drugs in aqueous solution," Advances in Colloid and Interface Science, vol. 55, pp. 271-303, 1995.

[12] S. Schreier, S. V. P. Malheiros, and E. De Paula, "Surface active drugs: self-association and interaction with membranes and surfactants. Physicochemical and biological aspects," Biochimica et Biophysica Acta, vol. 1508, no. 1-2, pp. 210-234, 2000.

[13] J. B. Chaires, N. Dattagupta, and D. M. Crothers, "Selfassociation of daunomycin," Biochemistry, vol. 21, no. 17, pp. 3927-3932, 1982.

[14] M. E. Nuss, T. L. James, M. A. Apple, and P. A. Kollman, "An NMR study of the interaction of daunomycin with dinucleotides and dinucleoside phosphates," Biochimica et Biophysica Acta, vol. 609, no. 1, pp. 136-147, 1980.

[15] M. Dalmark and H. H. Storm, "A Fickian diffusion transport process with features of transport catalysis. Doxorubicin transport in human red blood cells," Journal of General Physiology, vol. 78, no. 4, pp. 349-364, 1981.

[16] C. P. Burns, B. N. Haugstad, and J. A. North, "Membrane transport of mitoxantrone by L1210 leukemia cells," Biochemical Pharmacology, vol. 36, no. 6, pp. 857-860, 1987.

[17] B. Sundman-Engberg, U. Tidefelt, A. Gruber, and C. Paul, "Intracellular concentrations of mitoxantrone in leukemic cells in vitro vs in vivo," Leukemia Research, vol. 17, no. 4, pp. 347-352, 1993.
[18] A. Feofanov, S. Sharonov, F. Fleury, I. Kudelina, and I. Nabiev, "Quantitative confocal spectral imaging analysis of mitoxantrone within living K562 cells: intracellular accumulation and distribution of monomers, aggregates, naphtoquinoxaline metabolite, and drug-target complexes," Biophysical Journal, vol. 73, no. 6, pp. 3328-3336, 1997.

[19] L. L. Shen, J. Baranowski, and A. G. Pernet, "Mechanism of inhibition of DNA gyrase by quinolone antibacterials: specificity and cooperativity of drug binding to DNA," Biochemistry, vol. 28, no. 9, pp. 3879-3885, 1989.

[20] L. L. Shen, L. A. Mitscher, P. N. Sharma et al., "Mechanism of inhibition of DNA gyrase by quinolone antibacterials: a cooperative drug-DNA binding model," Biochemistry, vol. 28, no. 9, pp. 3886-3894, 1989.

[21] L. L. Shen, W. E. Kohlbrenner, D. Weigl, and J. Baranowski, "Mechanism of quinolone inhibition of DNA gyrase. Appearance of unique norfloxacin binding sites in enzyme-DNA complexes," Journal of Biological Chemistry, vol. 264, no. 5, pp. 2973-2978, 1989.

[22] T. Goto and T. Kondo, "Structure and molecular stacking of anthocyanins-flower color variation," Angewandte Chemie International Edition, vol. 30, pp. 17-33, 1991.

[23] T. Hoshino, "An approximate estimate of self-association constants and the self-stacking conformation of Malvin quinonoidal bases studied by ${ }^{1} \mathrm{H}$ NMR," Phytochemistry, vol. 30, no. 6, pp. 2049-2055, 1991.

[24] T. Escribano-Bailón, O. Dangles, and R. Brouillard, "Coupling reactions between flavylium ions and catechin," Phytochemistry, vol. 41, no. 6, pp. 1583-1592, 1996.

[25] D. Balasubramanian, V. Srinivas, V. G. Gaikar, and M. M. Sharma, "Aggregation behavior of hydrotropic compounds in aqueous solution," Journal of Physical Chemistry, vol. 93, no. 9, pp. 3865-3870, 1989.

[26] R. C. Da Silva, M. Spitzer, L. H. M. Da Silva, and W. Loh, "Investigations on the mechanism of aqueous solubility increase caused by some hydrotropes," Thermochimica Acta, vol. 328, no. 1-2, pp. 161-167, 1999.

[27] D. Horter and J. B. Dressman, "Influence of physicochemical properties on dissolution of drugs in the gastrointestinal tract," Advanced Drug Delivery Reviews, vol. 46, pp. 75-87, 2001.

[28] Y. V. Frenkel, A. D. Clark, K. Das et al., "Concentration and $\mathrm{pH}$ dependent aggregation of hydrophobic drug molecules and relevance to oral bioavailability," Journal of Medicinal Chemistry, vol. 48, no. 6, pp. 1974-1983, 2005.

[29] M. R. DeFelippis, R. E. Chance, and B. H. Frank, "Insulin selfassociation and the relationship to pharmacokinetics and pharmacodynamics," Critical Reviews in Therapeutic Drug Carrier Systems, vol. 18, no. 2, pp. 201-264, 2001.

[30] R. Ganapathi, D. Grabowski, H. Schmidt, A. Yen, and G. Iliakis, "Modulation of adriamycin and N-trifluoroacetyladriamycin14-valerate induced effects on cell cycle traverse and cytotoxicity in P388 mouse leukemia cells by caffeine and the calmodulin inhibitor trifluoperazine," Cancer Research, vol. 46, pp. 5553$5557,1986$.

[31] G. Iliakis, M. Nusse, R. Ganapathi, J. Egner, and A. Yen, "Differential reduction by caffeine of adriamycin induced cell killing and cell cycle delays in Chinese hamster V79 cells," International Journal of Radiation Oncology. Biology. Physics, vol. 12, pp. 1987-1995, 1986.

[32] F. Traganos, B. Kaminska-Eddy, and Z. Darzynkiewicz, "Caffeine reverses the cytotoxic and cell kinetic effects of 
Novantrone (mitoxantrone)," Cell Proliferation, vol. 24, no. 3, pp. 305-319, 1991.

[33] F. Traganos, J. Kapuscinski, and Z. Darzynkiewicz, "Caffeine modulates the effects of DNA-intercalating drugs in vitro: a flow cytometric and spectrophotometric analysis of caffeine interaction with novantrone, doxorubicin, ellipticine, and the doxorubicin analogue AD1981," Cancer Research, vol. 51, no. 14, pp. 3682-3689, 1991.

[34] C. Perez, F. Pelayo, N. E. Vilaboa, and P. Aller, "Caffeine attenuates the action of amsacrine and etoposide in U-937 cells by mechanisms which involve inhibition of RNA synthesis," International Journal of Cancer, vol. 57, no. 6, pp. 889-893, 1994.

[35] Y. Sadzuka, E. Mochizuki, and Y. Takino, "Mechanism of caffeine modulation of the antitumor activity of adriamycin," Toxicology Letters, vol. 75, no. 1-3, pp. 39-49, 1995.

[36] J. J. Roberts, "Mechanism of potentiation by Caffeine of genotoxic damage induced by physical and chemical agents," in DNA Repair and Its Inhibitors, A. Colins, C. S. Dowens, and R. T. Johnson, Eds., pp. 193-216, IRL Press, Oxford, UK, 1984.

[37] J. Piosik, M. Zdunek, and J. Kapuscinski, “The modulation by xanthines of the DNA-damaging effect of polycyclic aromatic agents-part 2. The stacking complexes of caffeine with doxorubicin and mitoxantrone," Biochemical Pharmacology, vol. 63, no. 4, pp. 635-646, 2002.

[38] G. M. Hill, D. M. Moriarity, and W. N. Setzer, "Attenuation of cytotoxic natural product DNA intercalating agents by caffeine," Scientia Pharmaceutica, vol. 79, no. 4, pp. 729-747, 2011.

[39] J. Piosik, A. Gwizdek-Wisniewska, K. Ulanowska, J. Ochocinski, A. Czyz, and G. Wegrzyn, "Methylxanthines (caffeine, pentoxifylline and theophylline) decrease the mutagenic effect of daunomycin, doxorubicin and mitoxantrone," Acta Biochimica Polonica, vol. 52, no. 4, pp. 923-926, 2005.

[40] F. Traganos, J. Kapuscinski, J. Gong, B. Ardelt, R. J. Darzynkiewicz, and Z. Darzynkiewicz, "Caffeine prevents apoptosis and cell cycle effects induced by camptothecin or topotecan in HL-60 cells," Cancer Research, vol. 53, no. 18, pp. 4613-4618, 1993.

[41] S. A. Khalil, L. K. El Khordagui, and A. M. Saleh, "Interaction of caffeine with phenothiazine derivatives," International Journal of Pharmaceutics, vol. 16, no. 3, pp. 271-283, 1983.

[42] H. Kimura and T. Aoyama, "Decrease in sensitivity to ethidium bromide by caffeine, dimethylsulfoxide or 3-aminobenzamide due to reduced permeability," Journal of PharmacobioDynamics, vol. 12, no. 10, pp. 589-595, 1989.

[43] K. Ulanowska, J. Piosik, A. Gwizdek-Wisniewska, and G. Wegrzyn, "Formation of stacking complexes between caffeine (1,2,3-trimethylxanthine) and 1-methyl-4-phenyl-1,2,3,6tetrahydropyridine may attenuate biological effects of this neurotoxin," Bioorganic Chemistry, vol. 33, pp. 402-413, 2005.

[44] J. Kapuscinski, B. Ardelt, J. Piosik, M. Zdunek, and Z. Darzynkiewicz, "The modulation of the DNA-damaging effect of polycyclic aromatic agents by xanthines-part 1. Reduction of cytostatic effects of quinacrine mustard by caffeine," Biochemical Pharmacology, vol. 63, no. 4, pp. 625-634, 2002.

[45] J. Piosik, K. Ulanowska, A. Gwizdek-Wiśniewska, A. Czyz, J. Kapuściński, and G. Wȩgrzyn, "Alleviation of mutagenic effects of polycyclic aromatic agents (quinacrine mustard, ICR-191 and ICR-170) by caffeine and pentoxifylline," Mutation Research, vol. 530, no. 1-2, pp. 47-57, 2003.

[46] A. Woziwodzka, A. Gwizdek-Wiśniewska, and J. Piosik, "Caffeine, pentoxifylline and theophylline form stacking complexes with IQ-type heterocyclic aromatic amines," Bioorganic Chemistry, vol. 39, no. 1, pp. 10-17, 2011.

[47] D.-H. Chin, H.-H. Li, H.-M. Kuo, P.-D. Lee Chao, and C.-W. Liu, "Neocarzinostatin as a probe for DNA protection activitymolecular interaction with caffeine," Molecular Carcinogenesis, vol. 51, pp. 327-338, 2012.

[48] R. W. Larsen, R. Jasuja, R. K. Hetzler, P. T. Muraoka, V. G. Andrada, and D. M. Jameson, "Spectroscopic and molecular modeling studies of caffeine complexes with DNA intercalators," Biophysical Journal, vol. 70, no. 1, pp. 443-452, 1996.

[49] D. B. Davies, D. A. Veselkov, L. N. Djimant, and A. N. Veselkov, "Hetero-association of caffeine and aromatic drugs and their competitive binding with a DNA oligomer," European Biophysics Journal, vol. 30, no. 5, pp. 354-366, 2001.

[50] M. B. Lyles and I. L. Cameron, "Caffeine and other xanthines as cytochemical blockers and removers of heterocyclic dna intercalators from chromatin," Cell Biology International, vol. 26, pp. 145-154, 2002.

[51] I. M. Johnson, S. G. Bhuvan Kumar, and R. Malathi, "Deintercalation of ethidium bromide and acridine orange by xanthine derivatives and their modulatory effect on anticancer agents," Journal of Biomolecular Structure \& Dynamics, vol. 20, pp. 677-685, 2003.

[52] E. Bedner, L. Du, F. Traganos, and Z. Darzynkiewicz, "Caffeine dissociates complexes between DNA and intercalating dyes: application for bleaching fluorochrome-stained cells for their subsequent restaining and analysis by laser scanning cytometry," Cytometry, vol. 43, pp. 38-45, 2001.

[53] M. P. Evstigneev, V. V. Khomich, and D. B. Davies, "Complexation of anthracycline drugs with DNA in the presence of caffeine," European Biophysics Journal, vol. 36, no. 1, pp. 1-11, 2006.

[54] M. P. Evstigneev, V. P. Evstigneev, and D. B. Davies, "NMR investigation of the effect of caffeine on the hetero-association of an anticancer drug with a vitamin," Chemical Physics Letters, vol. 432, no. 1-3, pp. 248-251, 2006.

[55] M. P. Evstigneev, V. P. Evstigneev, and D. B. Davies, "A method for analysis of multicomponent systems of interacting aromatic molecules in solution," Journal of Chemical Physics, vol. 127, no. 15, Article ID 154511, 2007.

[56] M. P. Evstigneev, V. P. Evstigneev, A. A. H. Santiago, and D. B. Davies, "Effect of a mixture of caffeine and nicotinamide on the solubility of vitamin (B2) in aqueous solution," European Journal of Pharmaceutical Sciences, vol. 28, no. 1-2, pp. 59-66, 2006.

[57] J. Kapuscinski and M. Kimmel, "Thermodynamical model of mixed aggregation of intercalators with caffeine in aqueous solution," Biophysical Chemistry, vol. 46, no. 2, pp. 153-163, 1993.

[58] M. Zdunek, J. Piosik, and J. Kapuscinski, “Thermodynamical model of mixed aggregation of ligands with caffeine in aqueous solution. Part II," Biophysical Chemistry, vol. 84, no. 1, pp. 77-85, 2000.

[59] D. B. Davies, D. A. Veselkov, M. P. Evstigneev, and A. N. Veselkov, "Self-association of antitumour agent Novantrone (Mitoxamtrone) and its hetero-association with Caffeine," Perkin Transactions II, vol. 1, pp. 61-67, 2001.

[60] M. B. Lyles, I. L. Cameron, and H. R. Rawls, "Structural basis for the binding affinity of xanthines with the DNA intercalator acridine orange," Journal of Medicinal Chemistry, vol. 44, pp. 4650-4660, 2001.

[61] M. B. Lyles and I. I. Cameron, "Interactions of the DNA intercalator acridine orange, with itself, with caffeine, and with 
double stranded DNA," Biophysical Chemistry, vol. 96, pp. 5376, 2002.

[62] M. P. Evstigneev, K. A. Rybakova, and D. B. Davies, "Complexation of norfloxacin with DNA in the presence of caffeine," Biophysical Chemistry, vol. 121, no. 2, pp. 84-95, 2006.

[63] P. A. Bolotin, S. F. Baranovsky, and M. P. Evstigneev, "Spectrophotometric investigation of the hetero-association of Caffeine and thiazine dye in aqueous solution," Spectrochimica Acta Part A, vol. 64, no. 3, pp. 693-697, 2006.

[64] D. D. Andrejuk, A. A. Hernandez Santiago, V. V. Khomich, V. K. Voronov, D. B. Davies, and M. P. Evstigneev, "Structural and thermodynamic analysis of the hetero-association of theophylline with aromatic drug molecules," Journal of Molecular Structure, vol. 889, no. 1-3, pp. 229-236, 2008.

[65] A. A. Hernandez Santiago, D. D. Andrejuk, A. M. Cervantes Tavera, D. B. Davies, and M. P. Evstigneev, "Complexation of biologically active aromatic compounds with DNA in the presence of theophylline," Journal of Biological Physics, vol. 35, no. 2, pp. 115-126, 2009.

[66] J. Piosik, K. Wasielewski, A. Woziwodzka, W. Śledź, and A. Gwizdek-Wiśniewska, "De-intercalation of ethidium bromide and propidium iodine from DNA in the presence of caffeine," Central European Journal of Biology, vol. 5, no. 1, pp. 59-66, 2010.

[67] M. P. Evstigneev, A. A. Mosunov, V. P. Evstigneev, H. G. Parkes, and D. B. Davies, "Quantification of the interceptor action of caffeine on the in vitro biological effect of the anti-tumour agent topotecan," European Biophysics Journal, vol. 40, no. 8, pp. 969980, 2011.

[68] A. Osowski, M. Pietrzak, Z. Wieczorek, and J. Wieczorek, "Natural compounds in the human diet and their ability to bind mutagens prevents DNA-mutagen intercalation," Journal of Toxicology and Environmental Health Part A, vol. 73, no. 1718, pp. 1141-1149, 2010.

[69] A. S. Buchelnikov, A. A. Hernandez Santiago, M. Gonzalez Flores, R. Vazquez Ramirez, D. B. Davies, and M. P. Evstigneev, "General analysis of competitive binding in drug-interceptorDNA systems," European Biophysics Journal, vol. 41, pp. 273283, 2012.

[70] A. A. Hernandez Santiago, M. Gonzalez Flores, and S. A. Rosas Castilla, " $\mathrm{H}$ NMR study of the complexation of aromatic drugs with dimethylxanthine derivatives," Journal of Molecular Structure, vol. 1010, pp. 139-145, 2012.

[71] L. S. Kan, P. N. Borer, D. M. Cheng, and P. O. P. Ts'o, " ${ }^{\prime 1} \mathrm{H}$ - and ${ }^{13} \mathrm{C}-\mathrm{NMR}$ studies on caffeine and its interaction with nucleic acids," Biopolymers, vol. 19, no. 9, pp. 1641-1654, 1980.

[72] H. Fritzsche, I. Petri, H. Schütz, K. Weller, P. Sedmera, and H. Lang, "On the interaction of caffeine with nucleic acids-III. ${ }^{1} \mathrm{H}$ NMR studies of caffeine- 5 '-adenosine monophosphate and caffeine-poly(riboadenylate) interactions," Biophysical Chemistry, vol. 11, no. 1, pp. 109-119, 1980.

[73] H. Fritzsche, H. Lang, H. Sprinz, and W. Pohle, "On the interaction of caffeine with nucleic acids-IV. Studies of the caffeine-DNA interaction by infrared and ultraviolet linear dichroism, proton and deuteron nuclear magnetic resonance," Biophysical Chemistry, vol. 11, no. 1, pp. 121-131, 1980.

[74] S. Tornaletti, P. Russo, S. Parodi, and A. M. Pedrini, "Studies on DNA binding of caffeine and derivatives: evidence of intercalation by DNA-unwinding experiments," Biochimica et Biophysica Acta, vol. 1007, no. 1, pp. 112-115, 1989.

[75] S. F. Baranovsky, P. A. Bolotin, M. P. Evstigneev, and D. N. Chernyshev, "Interaction of ethidium bromide and caffeine with DNA in aqueous solution," Journal of Applied Spectroscopy, vol. 76, no. 1, pp. 132-139, 2009.

[76] M. P. Evstigneev, A. O. Lantushenko, V. P. Evstigneev, Y. V. Mykhina, and D. B. Davies, "Quantitation of the molecular mechanisms of biological synergism in a mixture of DNAacting aromatic drugs," Biophysical Chemistry, vol. 132, no. 2-3, pp. 148-158, 2008.

[77] J. L. Quiles, J. R. Huertas, M. Battino, J. Mataix, and M. C. Ram'irez-Tortosa, "Antioxidant nutrients and adriamycin toxicity," Toxicology, vol. 180, no. 1, pp. 79-95, 2002.

[78] A. Ramu, M. M. Mehta, J. Liu, I. Turyan, and A. Aleksic, "The riboflavin-mediated photooxidation of doxorubicin," Cancer Chemotherapy and Pharmacology, vol. 46, no. 6, pp. 449-458, 2000.

[79] A. P. Odin, "Vitamins as antimutagens: advantages and some possible mechanisms of antimutagenic action," Mutation Research, vol. 386, no. 1, pp. 39-67, 1997.

[80] G. B. Raiczyk and J. Pinto, "Inhibition of flavin metabolism by adriamycin in skeletal muscle," Biochemical Pharmacology, vol. 37, no. 9, pp. 1741-1744, 1988.

[81] E. D. Kharasch and R. F. Novak, "The molecular basis for complexation of adriamycin with flavin mononucleotide and flavin adenine dinucleotide," Archives of Biochemistry and Biophysics, vol. 212, no. 1, pp. 20-36, 1981.

[82] E. D. Kharasch and R. F. Novak, "Structural and mechanistic related to antitumor antibiotics," Archives of Biochemistry and Biophysics, vol. 234, pp. 497-512, 1984.

[83] A. Galat, "Interaction of riboflavin binding protein with riboflavin, quinacrine, chlorpromazine and daunomycin," International Journal of Biochemistry, vol. 20, no. 9, pp. 1021-1029, 1988.

[84] A. W. Wood, J. M. Sayer, H. L. Newmark et al., "Mechanism of the inhibition of mutagenicity of a benzo[a]pyrene 7,8-diol 9,10epoxide by riboflavin $5^{\prime}$-phosphate," Proceedings of the National Academy of Sciences of the United States of America, vol. 79, no. 17, pp. 5122-5126, 1982.

[85] J. Pangrekar, K. Krishnaswamy, and V. Jagadeesan, "Effects of riboflavin deficiency and riboflavin administration on carcinogen-DNA binding," Food and Chemical Toxicology, vol. 31, no. 10, pp. 745-750, 1993.

[86] M. A. Munoz, C. Carmona, J. Hidalgo, P. Guardado, and M. Balon, "Molecular associations of flavins with betacarbolines and related indoles," Bioorganic and Medicinal Chemistry, vol. 3, no. 1, pp. 41-47, 1995.

[87] A. Codoner, I. S. Monzo, C. Ortiz, and A. Olba, "Spectroscopic study of molecular associations between riboflavin and some betacarboline derivatives," Journal of the Chemical Society, Perkin Transactions, vol. 2, pp. 107-111, 1989.

[88] A. Codoner, P. Medina, C. Ortiz, and E. Jover, "Spectroscopic study of molecular associations between riboflavin and some (dihydro) $\beta$-carboline derivatives," Spectrochimica Acta, vol. 49, pp. 321-327, 1993.

[89] A. Codoner, I. S. Monzo, F. Tomas, and R. Valero, "Spectroscopic study of intermolecular complexes between FAD and some $\beta$-carboline derivatives," Spectrochimica Acta, vol. 42, no. 7, pp. 765-769, 1986.

[90] A. Codoner, I. S. Monzo, P. Medina, and F. Tomas, "Spectroscopic study of molecular associations between flavins FAD and RFN and some indole derivatives," Spectrochimica Acta, vol. 43, pp. 389-394, 1987. 
[91] A. N. Veselkov, M. P. Evstigneev, and A. O. Rozvadovska, "A structural and thermodynamic analysis of novatrone and flavin mononucleotide heteroassociation in aqueous solution by ${ }^{1} \mathrm{H}$ NMR Spectroscopy," Russian Journal of Bioorganic Chemistry, vol. 31, pp. 453-459, 2005.

[92] M. P. Evstigneev, V. Y. Mykhina, and D. B. Davies, “Complexation of daunomycin with a DNA oligomer in the presence of an aromatic vitamin $\left(\mathrm{B}_{2}\right)$ determined by NMR spectroscopy," Biophysical Chemistry, vol. 118, pp. 118-127, 2005.

[93] A. N. Veselkov, M. P. Evstigneev, A. O. Rozvadovskaya, Y. V. Mukhina, K. A. Rybakova, and D. B. Davies, " ${ }^{1} \mathrm{H}$ NMR study of the complexation of aromatic molecules of an antibiotic and a vitamin in aqueous solution: heteroassociation of actinomycin D and flavin mononucleotide," Biophysics, vol. 50, no. 1, pp. 2027, 2005.

[94] M. P. Evstigneev, A. O. Rozvadovskaya, A. S. Chubarov, A. A. Hernandez Santiago, D. B. Davies, and A. N. Veselkov, "Structural and thermodynamic analysis of heteroassociation of daunomycin and flavin mononucleotide molecules in water by ${ }^{1}$ H NMR spectroscopy," Journal of Structural Chemistry, vol. 46, no. 1, pp. 67-74, 2005.

[95] M. P. Evstigneev, K. A. Rybakova, and D. B. Davies, "Heteroassociation of antibiotic norfloxacin with aromatic vitamins in aqueous solution," Biophysics, vol. 51, no. 4, pp. 592-598, 2006.

[96] A. A. Mosunov, V. V. Kostjukov, and M. P. Evstigneev, "Studies by means of ${ }^{1} \mathrm{H}$ NMR spectroscopy of complex formation of aromatic biologically active compounds with antibiotic topotecan," Ukrainian Biochemical Journal, vol. 84, pp. 61-72, 2012.

[97] M. P. Evstigneev, Y. V. Mukhina, and D. B. Davies, " ${ }^{\text {H } H ~ N M R ~}$ study of the hetero-association of flavin-mononucleotide with mutagenic dyes: ethidium bromide and proflavine," Molecular Physics, vol. 104, no. 4, pp. 647-654, 2006.

[98] Y. Mizuki, I. Fujiwara, and T. Yamaguchi, "Pharmacokinetic interactions related to the chemical structures of fluoroquinolones," Journal of Antimicrobial Chemotherapy, vol. 37, pp. 41-55, 1996.

[99] K. C. Yoovathaworn, K. Sriwatanakul, and A. Thithapandha, "Influence of caffeine on aspirin pharmacokinetics," European Journal of Drug Metabolism and Pharmacokinetics, vol. 11, no. 1, pp. 71-76, 1986.

[100] A. N. Veselkov, M. P. Evstigneev, A. O. Rozvadovskaya et al., " ${ }^{\text {} H}$ NMR structural and thermodynamical analysis of the heteroassociation of daunomycin and novatrone in aqueous solution," Journal of Molecular Structure, vol. 701, no. 1-3, pp. 31-37, 2004.

[101] D. B. Davies, M. P. Evstigneev, D. A. Veselkov, and A. N. Veselkov, "Hetero-association of anticancer antibiotics in aqueous solution: NMR and molecular mechanics analysis," Biophysical Chemistry, vol. 117, no. 2, pp. 111-118, 2005.

[102] M. P. Evstigneev, A. O. Rozvadovskaya, O. V. Zubchenok, Y. V. Mukhina, D. B. Davies, and A. N. Veselkov, "Analysis by means of ${ }^{1} \mathrm{H}$ NMR spectroscopy of heteroassociaion in water solution of antitumor antibiotics daunomycin and actinomycin D," Russian Journal of Organic Chemistry, vol. 41, no. 8, pp. 11581164, 2005.

[103] M. P. Evstigneev, K. A. Rybakova, and D. B. Davies, "Formation of complexes of antimicrobial agent norfloxacin with antitumor antibiotics of anthracycline series," Russian Journal of Physical Chemistry A, vol. 81, no. 5, pp. 802-807, 2007.

[104] J. L. Bernier, M. Lohez, N. Helbecque, and J. P. Henichart, "Effect of combination of m-AMSA and doxorubicin on their redox properties and on DNA cleavage," Chemico-Biological Interactions, vol. 70, no. 1-2, pp. 103-115, 1989.
[105] M. Sorensen, M. Sehested, and P. B. Jensen, "pH-Dependent regulation of camptothecin-induced cytotoxicity and cleavable complex formation by the antimalarial agent chloroquine," Biochemical Pharmacology, vol. 54, no. 3, pp. 373-380, 1997.

[106] B. S. Sorensen, P. B. Jensen, M. Sehested et al., "Antagonistic effect of aclarubicin on camptothecin induced cytotoxicity: role of topoisomerase I," Biochemical Pharmacology, vol. 47, no. 11, pp. 2105-2110, 1994.

[107] B. C. Baguley, “The possible role of electron-transfer complexes in the antitumour action of amsacrine analogues," Biophysical Chemistry, vol. 35, pp. 203-212, 1990.

[108] L. M. Davis, J. D. Harvey, and B. C. Baguley, "Electron donor properties of the antitumour drug amsacrine as studied by fluorescence quenching of DNA-bound ethidium," ChemicoBiological Interactions, vol. 62, pp. 45-58, 1987.

[109] G. S. Ridge, C. Bailly, D. E. Graves, and M. J. Waring, "Daunomycin modifies the sequence-selective recognition of DNA by actinomycin," Nucleic Acids Research, vol. 22, no. 24, pp. 52415246, 1994.

[110] L. Blau and R. Bittman, "Equilibrium and kinetic measurements of actinomycin binding to deoxyribonucleic acid in the presence of competing drugs," Molecular Pharmacology, vol. 11, no. 6, pp. 716-721, 1975.

[111] T. A. Beerman, J. M. Woynarowski, and M. McHugh, "Modylation of topoisomerase targeted drugs by minor-groove binding agents," in DNA Topoisomerases in Cancer, M. Potmesil and K. W. Kohn, Eds., pp. 172-181, Oxford University Press, New York, NY, USA, 1991

[112] A. H. J. Wang, Y. G. Gao, Y. C. Liaw, and Y. K. Li, "Formaldehyde cross-links daunorubicin and DNA efficiently: HPLC and X-ray diffraction studies," Biochemistry, vol. 30, no. 16, pp. 3812-3815, 1991.

[113] H. Zhang, Y. G. Gao, G. A. Van der Marel, J. H. Van Boom, and A. H. J. Wang, "Simultaneous incorporations of two anticancer drugs into DNA. The structures of formaldehyde-cross linked adducts of daunorubicin-d(CG(araC)G0CG) and doxorubicin$\mathrm{d}(\mathrm{CA}(\mathrm{araC}) \mathrm{GTG})$ complexes at high resolution," Journal of Biological Chemistry, vol. 268, no. 14, pp. 10095-10101, 1993. 